\title{
Bilateral diaphragm paralysis after cardiac surgery with topical hypothermia
}

\author{
J Efthimiou, J Butler, M K Benson, S Westaby
}

\begin{abstract}
Bilateral diaphragm paralysis is a rare but important complication of open heart surgery. Two cases were found among 360 prospectively studied patients undergoing open heart surgery during one year. Both patients had insulin dependent diabetes with peripheral neuropathy and this may have contributed to their diaphragm paralysis. The patients were studied postoperatively for one year with measurements of lung function, nocturnal oximetry, diaphragmatic function, and phrenic nerve conduction. Treatment with intermittent positive airway pressure ventilation by nasal mask was effective in both patients. After nine months one patient had recovered completely with normal phrenic nerve conduction and diaphragmatic function; the other continues most of his normal daytime activities, but still requires nasal positive airway pressure ventilation for six hours at night.
\end{abstract}

In the last two decades unilateral and rarely bilateral diaphragm paralysis have been increasingly recognised as complications of open heart surgery. The diaphragm paralysis has been attributed to cold injury of the phrenic nerve as a result of the topical iced or slush saline used for myocardial protection, ${ }^{1-3}$

Table 1 Postoperative pulmonary function values, mouth pressures, arterial oxygen and carbon dioxide tensions $\left(\mathrm{PaO}_{2}, \mathrm{PaCO}_{2}\right)$, and nocturnal arterial oxygen saturation $\left(\mathrm{SaO}_{2}\right)$

\begin{tabular}{|c|c|c|c|c|}
\hline & \multicolumn{2}{|l|}{ Patient 1} & \multicolumn{2}{|l|}{ Patient 2} \\
\hline & Sitting & Supine & Sitting & Supine \\
\hline $\begin{array}{l}\mathrm{FEV}_{1}(\mathrm{l}) \\
\text { FVC (1) } \\
\operatorname{PImax}\left(\mathrm{cm} \mathrm{H}_{2} \mathrm{O}\right) \\
\operatorname{PEmax}\left(\mathrm{cm} \mathrm{H}_{2} \mathrm{O}\right)\end{array}$ & $\begin{aligned} & 1 \cdot 10 \\
& 1 \cdot 30 \\
&-45 \\
& 75\end{aligned}$ & $\begin{array}{r}0.65 \\
0 \cdot 70 \\
-35 \\
70\end{array}$ & $\begin{array}{r}0.95 \\
1.35 \\
-35 \\
65\end{array}$ & $\begin{array}{r}0.55 \\
0.60 \\
-25 \\
60\end{array}$ \\
\hline Pdi $\max \left(\mathrm{cm} \mathrm{H}_{2} \mathrm{O}\right)$ & $\begin{array}{r}T L C \\
4\end{array}$ & $\underset{5}{\text { Sniff }}$ & $\begin{array}{r}T L C \\
6\end{array}$ & $\begin{array}{r}\text { Sniff } \\
8\end{array}$ \\
\hline $\begin{array}{l}\mathrm{PaO}_{2}(\mathrm{kPa}) \\
\mathrm{PaCO}_{2}(\mathrm{kPa})\end{array}$ & $\begin{array}{r}\text { Sitting } \\
8 \cdot 19 \\
3 \cdot 90\end{array}$ & $\begin{array}{r}\text { Supine } \\
7 \cdot 14 \\
5 \cdot 18\end{array}$ & $\begin{array}{r}\text { Sitting } \\
8.02 \\
4 \cdot 36\end{array}$ & $\begin{array}{r}\text { Supine } \\
6.94 \\
5.90\end{array}$ \\
\hline & $\begin{array}{l}\text { Before } \\
N P A P\end{array}$ & $\begin{array}{l}\text { During } \\
\text { NPAP }\end{array}$ & $\begin{array}{l}\text { Before } \\
N P A P\end{array}$ & $\begin{array}{l}\text { During } \\
\text { NPAP }\end{array}$ \\
\hline $\begin{array}{l}\text { Lowest overnight } \mathrm{SaO}_{2}(\%) \\
\mathrm{SaO}_{2} \text { dips over } 4 \% \text { in } 6 \text { hours' } \\
\text { sleep (n) }\end{array}$ & $\begin{array}{l}81 \cdot 0 \\
32\end{array}$ & $\begin{array}{c}92 \cdot 0 \\
3\end{array}$ & $\begin{array}{l}80 \cdot 6 \\
57\end{array}$ & $\begin{array}{c}91 \cdot 0 \\
5\end{array}$ \\
\hline
\end{tabular}

$\mathrm{FEV}_{1}$-forced expiratory volume in one second; FVC_forced vital capacity; PImax-maximum inspiratory mouth pressure; PEmax - maximum expiratory mouth pressure; Pdimax-maximum transdiaphragmatic pressure; TLC-total lung capacity; Sniff-maximum inspiratory sniff; NPAP - nasal positive airway pressure ventilation. though this is debated. ${ }^{1}$ Only a few cases of bilateral diaphragm paralysis following open heart surgery have been reported ${ }^{4-6}$ since the original description by Scannell in 1963 . Why some patients develop bilateral as opposed to unilateral diaphragm paralysis has never been clearly explained, and no definitive treatment strategy has been agreed.

Intermittent positive airway pressure ventilation delivered by nasal mask is noninvasive and simple to use and has been shown to benefit patients with various neuromuscular disorders causing diaphragm weakness. $^{8-10}$ We present two patients with bilateral diaphragm paralysis following open heart surgery, both with insulin dependent diabetes, who were successfully treated with nasal positive airway pressure ventilation.

\section{Methods}

For a prospective study of phrenic nerve conduction before and after elective cardiac surgery we studied 360 consecutive adult patients having open heart surgery. Two of these, both with insulin dependent diabetes, developed bilateral diaphragm paralysis.

Two additional patients, from a further 390 consecutive adult patients studied retrospectively for the year before the prospective study, were also found to have bilateral diaphragm paralysis. One of these latter patients had insulin dependent diabetes with a mild peripheral neuropathy; the other had a right sided diaphragm paralysis before operation as a result of brachial neuritis three years previously. The two patients in the prospective group were studied in detail and form the basis of this report.

\section{Case reports}

PATIENT 1

A 57 year old non-smoking man underwent quadruple aortocoronary bypass grafting for angina resistant to medical treatment. He had longstanding insulin dependent diabetes and a peripheral neuropathy (predominantly sensory and affecting only the lower limbs clinically), nephropathy, and retinopathy of two years' duration. During surgery myocardial protection was achieved during 73 minutes of aortic cross clamping with cold cardioplegia (modified St Thomas's hospital solution), core cooling to $28^{\circ} \mathrm{C}$, and topical hypothermia with iced and slush saline. Weaning from assisted ventilation and extubation took four days. Subsequently, when he had left the intensive care unit, he complained of severe ortho- 
Table 2 Phrenic nerve conduction time and diaphragm compound muscle action potential $(C M A P)^{\star}$

\begin{tabular}{|c|c|c|c|c|}
\hline & \multicolumn{2}{|c|}{ Phrenic nerve conduction time ( $\mathrm{ms}$ ) } & \multicolumn{2}{|c|}{ Diaphragm CMAP ( $\boldsymbol{C} v)$} \\
\hline & Right & Left & Right & Left \\
\hline \multicolumn{5}{|l|}{ PATIENT 1} \\
\hline $\begin{array}{l}\text { Before operation } \\
1 \text { week after } \\
1 \text { month after } \\
9 \text { months after }\end{array}$ & $\begin{array}{l}8 \cdot 1 \\
\text { Absent } \\
\text { Absent } \\
9 \cdot 8\end{array}$ & $\begin{array}{l}8 \cdot 2 \\
\text { Absent } \\
\text { Absent } \\
11.9\end{array}$ & $\begin{array}{l}360 \\
\text { Absent } \\
\text { Absent } \\
350\end{array}$ & $\begin{array}{l}400 \\
\text { Absent } \\
\text { Absent } \\
280\end{array}$ \\
\hline \multicolumn{5}{|l|}{ PATIENT 2} \\
\hline $\begin{array}{l}\text { Before operation } \\
1 \text { week after } \\
1 \text { month after } \\
9 \text { months after }\end{array}$ & $\begin{array}{l}8 \cdot 3 \\
\text { Absent } \\
\text { Absent } \\
\text { Absent }\end{array}$ & $\begin{array}{l}8 \cdot 5 \\
\text { Absent } \\
\text { Absent } \\
\text { Absent }\end{array}$ & $\begin{array}{l}440 \\
\text { Absent } \\
\text { Absent } \\
\text { Absent }\end{array}$ & $\begin{array}{l}460 \\
\text { Absent } \\
\text { Absent } \\
\text { Absent }\end{array}$ \\
\hline
\end{tabular}

^Normal ranges: phrenic nerve conduction time 5·8-9·1 ms; diaphragm CMAP 350-1100 $\mu \mathrm{v}$.

pnoea, shortness of breath on minimal exertion, disturbed sleep, and daytime hypersomnolence. He was initially treated for left ventricular failure with little improvement. The diagnosis of bilateral diaphragm paralysis was made six days after operation, on the basis of his severe orthopnoea and pronounced abdominal paradox even when he was sitting upright.

His chest radiograph showed a bilaterally raised diaphragm with bilateral basal consolidation. Diaphragmatic screening showed severely reduced movement bilaterally, but no paradox. The forced expiratory volume in one second $\left(\mathrm{FEV}_{1}\right)$ and forced vital capacity (FVC) were reduced, consistent with a severe restrictive ventilatory defect (table 1 ). The FVC fell by $46.2 \%$ when he became supine. Maximum inspiratory mouth pressure ( $\left.P_{1} \max \right)$ was reduced and fell by $22.2 \%$ when he became supine. Analysis of arterial blood gases while he was sitting up and breathing room air showed hypoxaemia with a low carbon dioxide tension $\left(\mathrm{PaCO}_{2}\right)$ (table 1$)$. When he lay down his arterial oxygen tension $\left(\mathrm{PaO}_{2}\right)$ fell and $\mathrm{PaCO}_{2}$ rose. Transdiaphragmatic pressure (Pdi), measured with balloon tipped gastric and oesophageal catheters, was severely reduced at 4-5 (normal $>20$ ) $\mathrm{cm} \mathrm{H}_{2} \mathrm{O}$ during both a maximum inspiratory effort to total lung capacity (TLC) and a maximum sniff (table 1). ${ }^{11}$ Phrenic nerve conduction time was tested by stimulating the phrenic nerve percutaneously in the neck and recording the electromyogram (EMG) of the diaphragm from the lower chest wall with surface electrodes. ${ }^{12}$ Phrenic nerve conduction time and diaphragm compound muscle action potential were normal before operation but absent one and four weeks and six months postoperatively (table 2 ).

Treatment was started with intermittent positive airway pressure ventilation with a portable Life-Care ventilator (Thomas Respiratory System), delivered through a tight fitting nasal mask for eight hours each night. Nocturnal oximetry (finger pulse oximeter, Ohmeda Biox 3700) before the start of ventilation showed a mean overnight arterial oxygen saturation $\left(\mathrm{SaO}_{2}\right)$ of $89.5 \%$, a lowest recorded $\mathrm{SaO}_{2}$ of $81 \%$, and 32 dips in $\mathrm{SaO}_{2}$ of $4 \%$ or more during four hours of fragmented sleep while the patient was sitting propped up in bed (table 1). After two nights of adaptation to the nasal mask, ventilation was effective and well tolerated (table 1). Nine months later he was able to perform all his normal activities and walk several miles on the flat at a normal pace. He no longer required assisted ventilation at night and his orthopnoea and abdominal paradox had resolved. Phrenic nerve conduction time was now recordable, but slowed on both sides (table 2).

PATIENT 2

A 58 year old non-smoking man with severe mitral stenosis and angina underwent open mitral valvotomy and double coronary artery bypass grafting. He had longstanding insulin dependent diabetes with severe peripheral neuropathy, autonomic neuropathy, and diabetic retinopathy for at least four years. Myocardial protection during 56 minutes of aortic cross clamping was achieved by cold cardioplegia, core cooling, and topical iced and slush saline. He was extubated with difficulty 48 hours after operation. He became very short of breath 12 hours later with respiratory failure and required reintubation and assisted ventilation. Several subsequent attempts at weaning failed. On the eighth postoperative day pronounced orthopnoea and abdominal paradox were observed and a diagnosis of bilateral diaphragm paralysis was made.

His chest radiograph at this time showed a bilaterally raised diaphragm and diaphragmatic screening showed pronounced reduction of movement bilaterally, but no paradox. The FEV $_{1}$ and FVC were reduced, consistent with a severe restrictive ventilatory defect (table 1 ). The FVC fell by $55.5 \%$ when he became supine. $\mathrm{P}_{\mathrm{r}} \max$ was substantially reduced and fell by $28 \cdot 6 \%$ when he lay down. When upright and breathing room air he had hypoxaemia and a normal $\mathrm{PaCO}_{2}$ (table 1). When he lay down his $\mathrm{PaO}_{2}$ fell and $\mathrm{PaCO}_{2}$ increased. The Pdi during a maximum inspiratory effort to TLC and a maximum sniff was severely reduced at $6-8 \mathrm{~cm}$ $\mathrm{H}_{2} \mathrm{O}$ (table 1). Phrenic nerve conduction time and diaphragm compound muscle action potential were normal preoperatively but absent one week, four weeks and nine months after operation (table 2)

Treatment was started with nasal positive airway pressure ventilation six weeks after operation for eight hours each night. Nocturnal oximetry after he had started this showed an improvement in mean $\mathrm{SaO}_{2}$ from $87.4 \%$ to $94.5 \%$, with almost total resolution of nocturnal dips in $\mathrm{SaO}_{2}$ (table 1). Nine months later he still required assisted ventilation for six hours each night and had orthopnoea and abdominal paradox. He was however, managing to walk several hundred metres on the flat and coping with most of his normal daytime activities.

\section{Discussion}

Bilateral diaphragm paralysis after open heart surgery is an uncommon complication with few published reports. ${ }^{14-61415}$ The incidence of this complication in our unit was two cases in 360 patients studied prospectively over one year. 
Both these patients and one of the two patients identified in our retrospective study had insulin dependent diabetes. One of the two patients described by Kohorst et $a^{4}$ also had insulin dependent diabetes, further supporting our hypothesis that diabetes predisposes to phrenic nerve cold injury and diaphragm paralysis. All three of our diabetic patients had clinical evidence of peripheral neuropathy, of moderate severity in two. Possibly the phrenic nerves were also affected by subclinical neuropathy, though phrenic nerve conduction time was normal preoperatively. These findings suggest that further work on the sensitivity of diabetic nerves to cold injury is indicated.

Pronounced orthopnoea and abdominal paradox, in association with a fall in vital capacity of about $50 \%$ when the patient lies supine, strongly suggests the diagnosis of bilateral diaphragm paralysis, ${ }^{16}{ }^{17}$ and led to a positive diagnosis in all our patients. Diaphragmatic screening may be helpful in showing that diaphragm movement is reduced or absent, but paradoxical movement is frequently not present. ${ }^{16}$

The measurement of phrenic nerve conduction time is a useful technique for assessing phrenic nerve function, ${ }^{412}$ and currently may be the most sensitive method available for identifying different degrees of phrenic nerve cold injury. The initial absence of phrenic nerve conduction in our patients after surgery suggests that cold injury may result in axonal degeneration or severe demyelination of the phrenic nerves, or both. Evidence of such lesions has been seen at necropsy ${ }^{57}$ and in experimental models of cold injury in animals. ${ }^{18}$ Prolongation of phrenic nerve conduction time due to milder degrees of cold injury may occur in up to $40 \%$ of patients after open heart surgery (unpublished data), and milder degrees of demyelination may be the best explanation for this.

Considerable morbidity and mortality are associated with bilateral diaphragm paralysis. Respiratory impairment may be well tolerated by day but becomes a serious problem during sleep, especially during rapid eye movement sleep. ${ }^{19}{ }^{20}$ Respiratory failure has generally been considered common in patients with bilateral diaphragm paralysis. ${ }^{16}$ Laroche et al, ${ }^{21}$ however, have recently challenged this point of view and suggested that it is rare unless the other respiratory muscles are also affected. In our patients the other respiratory muscles are unlikely to have been affected and, although respiratory failure did occur, it was mild and seen only when the patient was supine, particularly at night. Death is not uncommon after bilateral diaphragm paralysis, and in three of the 10 previously reported cases the patient died within the first six months after operation, the other seven patients requiring assisted ventilation for four to twelve months before recovering. ${ }^{4-615}$.

Negative pressure ventilation has been used to treat bilateral diaphragm paralysis in patients with neuromuscular disorders in the past, but it is often accompanied by complications and is cumbersome to use. ${ }^{223}$ Nasal positive airway pressure ventilation is a relatively new technique, which is simple to use, has few complications, and has been shown to be of benefit to patients with neuromuscular disorders and in hypoventilation associated with kyphoscoliosis. ${ }^{81024}$ After the initiation of nasal positive airway pressure ventilation in our patients the mean overnight $\mathrm{SaO}_{2}$ increased to normal levels and the dips in $\mathrm{SaO}_{2}$ were abolished. After nine months of this treatment one patient had fully recovered and, although the other patient continued to require assisted ventilation he was able to continue most of his normal daytime activities.

We conclude that diabetes mellitus, particularly with peripheral neuropathy, is a substantial risk factor for the development of bilateral diaphragm paralysis after open heart surgery when topical iced or slush saline is used for myocardial protection. We suggest that the latter should be avoided where possible or used in conjunction with a pericardial insulator in patients with diabetes and in those with previous phrenic nerve or diaphragm problems. Nasal positive airway pressure ventilation is a relatively simple and effective treatment. Measurement of phrenic nerve conduction time offers a useful technique for monitoring the recovery of phrenic nerve function after cold injury following cardiac surgery.

1 Large SR, Heywood LJ, Flower CD, Cory-Pearce R, Wallwork J, English TA. Incidence and aetiology of a raised hemidiaphragm after cardiopulmonary bypass. Thorax 1985;40:444-7.

2 Esposito RA, Spencer FC. The effect of pericardial insulation on hypothermic phrenic nerve injury during open heart surgery. Ann Thorac Surg 1987;43:303-8.

3 Efthimiou J, Hassam AB, Woodham $\mathrm{CH}$, Westaby S, Benson MK. Phrenic nerve cold injury: the cause of diaphragm paralysis following open heart surgery [abstract]. Thorax 1990;45:340P.

4 Kohorst WR, Schonfeld SA, Altman M. Bilateral diaphragmatic paralysis following topical cardiac hypothesis. Chest 1985;1:65-8.

5 Chandler KW, Rozas CJ, Kory RC, Goldman AL. Bilateral diaphragmatic paralysis complicating local cardiac hypothermia during open heart surgery [abstract]. $\mathrm{Am}$ Rev Respir Dis 1982;125:28.

6 Brown R, Khuri S, Solway J, Dowen K, Loring S, Slutsky AS. Phrenic nerve injury following topical hypothermia for myocardial protection during cardiac surgery [abstract]. Am Rev Respir Dis 1982;125:120.

7 McGoon DC, Mankin HT, Kirklin JW. Results of open heart operation for acquired aortic valve disease. $J$ Thorac Cardiovasc Surg 1963;45:47-66.

8 DiMarco AF, Connors AF, Altose MD. Management of chronic alveolar hypoventilation with nasal positive pressure breathing. Chest 1987;92:952-4.

9 Rodenstein DO, Stanescu DC, Delguste P. Adaptation to intermittent positive pressure ventilation applied through the nose during day and night. Eur Respir $J$ 1989;2:473-8.

10 Kerby GR, Mayer LS, Pingleton SK. Nocturnal positive pressure ventilation via nasal mask. Am Rev Respir Dis 1987;135:738-40.

11 Laroche CM, Mier AK, Moxham J, Green M. Diaphragm strength in patients with recent hemidiaphragm paralysis. Thorax 1988;43:170-4.

12 Mier A, Brophy C, Moxham J, Green M. Phrenic nerve stimulation in normal subjects and in patients with diaphragmatic weakness. Thorax 1987;42:885-8.

13 Rousou JA, Parker T, Engelman RM, Breyer RH. Phrenic nerve paresis associated with the use of iced slush and the cooling jacket for hypothermia. J Thorac Cardiovasc Surg 1985;89:921-5.

14 Markand ON, Moorthy SS, Mahomed Y, King RD, Brown $\mathrm{JW}$. Postoperative phrenic nerve palsy in patients with JW. Postoperative phrenic nerve palsy in patients
open heart surgery. Ann Thorac Surg 1985;39:68-73.

15 Cabrera MR, Edsell JR. Bilateral diaphragm paralysis associated with topical cardiac hypothermia. NY State $J$ Med 1987;Sept:514-6.

16 Newsom Davis J, Goldman M, Loh L, Casson M. Diaphragm function and alveolar hypoventilation. $Q \mathrm{~J} \mathrm{Med}$ 1976;45:87-100.

17 Green M, Moxham J. The respiratory muscles. Clin Sci 
1985;68:1-10.

18 Marco JD, Hahn JW, Barner HB. Topical cardiac hypothermia and phrenic nerve injury. Ann Thorac Surg 1977;23:235-7.

19 Efthimiou J, McLelland J, Round J, Gribbin HR, Loh L, Spiro SG. Diaphragm paralysis causing ventilatory failure in an adult with the rigid spine syndrome. Am Rev Respir Dis 1987;136:1483-5.

20 Skatrud JL, Iber C, McHugh N, Rasmussen H, Nichols D.

Determinants of hypoventilation during wakefulness and sleep in diaphragmatic paralysis. Am Rev Respir Dis 1980;121:587-93.

21 Laroche CM, Carroll N, Moxham J, Green M. Clinical significance of severe isolated diaphragm weakness. $\mathrm{Am}$ Rev Respir Dis 1988;138:862-6.

22 Scharf SM, Feldman NT, Goldman MD, Haut HZ, Bruce E, Ingram RH. Vocal cord closure. A cause of upper airway obstruction during controlled ventilation. $A m$ Rev Respir Dis 1978;117:391-7.

23 Simonds AK, Branthwaite MA. Efficiency of negative pressure ventilatory equipment [abstract]. Thorax 1985; 40:213.

24 Ellis ER, Bye PT, Bruderer JW, Sullivan CE. Treatment of respiratory failure during sleep in patients with neuromuscular disease. Am Rev Respir Dis 1987;135: 148-52. 